\title{
Knowledge of Speech Writing, Audience Analysis in Speech Delivery Among Senior Secondary Students in Ogun State
}

\author{
James, Nma C. *, Kalejaye, S. Abiola ${ }^{\text {*** }}$, Kparou, Hanoukoume Cyril ${ }^{* * *}$ \\ * Department of Education, School of Education and Humanities, Babcock University, Ilishan Remo, Ogun State \\ *** Department of Languages and Literary Studies, School of Education \& Humanities, Babcock University \\ *** Department of Languages and Literary Studies, School of Education \& Humanities, Babcock University
}

DOI: 10.29322/IJSRP.11.08.2021.p11631

http://dx.doi.org/10.29322/IJSRP.11.08.2021.p11631

\begin{abstract}
Speech writing, audience analysis and speech delivery are integral parts of language pedagogy. Diverse studies exist on speech writing, however, a paucity of studies exists on audience analysis and speech delivery. Therefore, this paper validated audience analysis and speech delivery skills of selected secondary school students in Ogun State, Nigeria. Descriptive Survey research design was used and population of the study comprised three purposively selected Senior Secondary Schools students in Ikenne Local Government Area in Ogun State. The schools were Isanbi Model Secondary School, Ilishan High School and Ikenne Comprehensive Secondary school respectively. The instrument used was a structured questionnaire which was validated through Cronbach. Data collected were analyzed statistically through descriptive statistics of mean and standard deviation. The findings revealed that students exhibited high level of knowledge in speech writing, but a low level of knowledge in audience analysis and speech delivery. Based on the findings, the study recommended that English language teachers should expedite actions to improve on the techniques they employ in teaching speech delivery and audience analysis. Also, school authorities should supply speech delivery equipment, tools such as computers, books etcetera) to enhance students' performance.
\end{abstract}

Index Terms- Speech Writing, Audience Analysis, Speech Delivery

\section{INTRODUCTION}

$S^{\mathrm{n}}$ peech writing and delivery are two distinct but inseparable arts traceable to classical antiquity Kamalu (2018). Both concepts and now taught in language pedagogy. Speech writing on the one hand, is the art of composing ideas on a given topic as though an audience was physically present, while speech delivery is the act of orally presenting the written ideas to a particular audience. Obviously, at the center of the two arts is the audience. Hence, audience analysis is imperative to determine the effectiveness of a speech delivered/ made.

Audience analysis is the process of taking due consideration of readership potentiality of the audience, that is what an audience would like to know and how they can best understand it. There are psychological, situational and demographic analysis of audience which the speech writer must take into cognizance before writing and delivering any speech. This implies that there are speeches meant for different categories of people. For instance, some speeches are meant for only the youths, while some are for adults. Also there are speeches that could benefit females more than males. Hence, speech writers need to do audience analysis before presenting speeches so as to have meaningful speech delivery

A speech writer must be versatile in the chosen area s/ he is writing about so that the audience can gain new knowledge from the speech. Some members of audience attend speech presentation mostly to acquire new skills and if this purpose be unsuccessful, the speech might be adjudged ineffective and useless. Therefore, the speech writer and presenter needs to understand that practice is the key to attaining excellence in speech delivery, because it is not enough to write the speech but it also offers mutual benefit to both the speech maker and the audience, particularly when the speech maker makes deliberate plan to rehearse, arrange the points to be made logically and practice the content of a speech in order to meet the needs of the audience. When the speech maker does all of the foregoing, $\mathrm{s} / \mathrm{he}$ is able to answer the questions that might emanate from the speech. Effective preparation is beneficial to the speech maker as it would prevent the speaker from being embarrassed by the audience (German, 2010)

Although secondary school students are exposed to speech writing and speech delivery, hardly are they taught audience analysis. Consequently, most senior secondary students have low knowledge in these areas and as a result lack competence in speech related activities. If these problem are not tackled during school years, such graduates will likely face difficulty in audience analysis. This study fills this gap.

This study utilizes the speech code theory which supports the understanding of diverse speech activities among cultures and teaching activities. To boost student's interest in speech activities, the theory advocates that students should appreciate the difference that exists among people when it comes to speech delivery. Thus, the theory explores the significance of speaking on the speech codes used by speakers and listeners to create and interpret their communication (Gerry, 2015)

As an objective of this paper, teachers need to encourage secondary school students to have mastery of speech writing, audience analysis and speech delivery so that they can engage themselves in speech writing when they graduate. A graduate from secondary school should be able to write and delivery 
speeches proficiently and be ready to measure up with their counterparts all over the globe.

\section{SPEECH WrITING}

A speech is a subset of communication. It is as diverse as communication itself as it is a conversation where a speaker gives information and dispenses knowledge to an audience. It could either be written or spoken. A good speech writer has mastery of some features and utilizes same when writing speeches. This includes bearing in mind that the speech should be relevant. Gallo (2014) opines that if a speech fails to address important issues bothering on the audience it may end up being ineffective. A good speech writer should ensure that the speech he is writing is relevant to the target audience.

A profient speech writer should be sure of the audience he is writing about and strive to make his speech audience-centered. The speech is meant for the audience; consequently any speech writer should understand this fact and ascertain whom he is writing the speech for. The writer of any speech should endeavor to write what the audience will benefit from. Additionally, a speech is meant to give information, therefore, the speech writer should write in such a way as to ensure that the listener or the audience will gain knowledge at the end of the speech. Alimolu, (2002) submits that good speech should project current and factual knowledge on the topic being discussed so that listeners or the audience will not waste their time in what will not benefit them, because time is so precious to be wasted on what is not beneficial.

To write a good speech, one needs to be mindful of the language and style to be used in writing the speech. Okwara (2012) submits that the language should be appealing and unambiguous. If the language is not appropriate, the good ideas and thoughts will be jeopardized and render the speech ineffective. The topic, aim and the audience of a particular speech should be taken into consideration when writing speech so that the language and understanding of the audience will flow with the speech.

There are some qualities which a good speech writer must possess so as to make for effective speech. These include 'masking' which is to wear the garb of another person. The writer of the speech should endeavor to write the speech and assume the expressive characteristics of the speaker (Gregory, 2010). This will convince the audience that the writer of the speech is also the presenter.

Also, the speech writer needs to be versatile in the area he is writing about. To attain this, he needs to read vast and acquire more knowledge in the topic s/he is writing about. As the audience is mostly heterogeneous, the speech writer should be careful in writing so that some members of the audience who may be knowledgeable in the topic will not fault what he has written. Even if it is a known topic, there must be additional information to what most people are already familiar with. For example, if it is online teaching method, where everyone is using zoom, there may be need to introduce Google classroom, etcetera as a way of adding to what the audience already knows.

There are various types of speeches ranging from expository speech which sheds light on a matter that appears hidden in a concept or a person. Illustrations or examples are used to aid the speech so that it will be effective. Also, there is inspirational speech which according to Cervantes \&Simon (2018) aims at studying the current situation of the target audience and tries to cause them to achieve what may seem difficult for them to embark on. Persuasive Speech tries to ensure the audience believes what the writer or the speaker is presenting. Analytical speech has to do with writing or presenting the speech in such a way that the speech is broken down for the audience to understand. The writer of analytical speech ensures that he is logical enough in his writing and presentation of the speech. There is a speech of introduction which aims at introducing the main speaker to the audience first before the commencement of the main speech. This is important because it serves as the introduction to the speaker (Lucas 2001). Another type of speech is Commemorative Speech which aims at eulogizing a person or group of people.

Writing speech starts with getting a befitting topic or title. Once the title is derived, the speech writer goes straight to writing the introduction of the speech. Under introduction, the speech writer should endeavor to ensure that the speech is inviting enough to attract the audience so that they will be anxious, zealous and tempted to listen to it. The introduction of the speech should be pungent so that the audience will hunger and taste for it.

The introductory aspect of the speech should be free from unnecessary preamble. This means that any material that is not related to the speech should be discarded. Sharp and straight forward statement that will cause the audience to be in suspense is allowed at the introductory stage of writing or presentation of the speech. A good speech should be audience-centered and promote good rapport between the speech presenter and the audience from the very beginning. In speech writing, the use of evidence is necessary. This means documents, books, interviews; etcetera should be used in backing up the speech. The speech writer should utilize materials that are current in writing the speech, because what some audience may be interested in a speech is to get current information and update their knowledge on what they already know. Hence, there is a need to get material from genuine sources. For example, assuming one wants to get information concerning the status of a university in Nigerian, the best place to get genuine information should be from the Federal Ministry of Education or National Universities Commission.

\section{SPEECH DELIVERY}

Speech delivery is the main purpose of writing speech. It could be delivered through verbal or written medium. Some speeches could be accessed after being presented to the audience. If the writer is the presenter of the speech, there is need to present the speech well. This could be attained through thorough rehearsal and practice before presentation (Lucas, 2001) If a speech is wellwritten and the delivery is poor, it renders the speech ineffective.

In speech delivery, it is important to know the physical setting of the speech. Adler \& Elemhost, (2008) submitted that if the venue of the speech is not conducive for the listener, it will affect the speech delivery because the audience may not pay attention to the speech. The seating arrangement should be neatly done to avoid rowdiness and noise. Jill (2017) stated that under the physical setting the person delivering the speech should find out how many people are expected to attend the speech, whether there will be need for public address system, whether the speech presenter will be on a platform or on a stage, how close the 
presenter will be to the audience, whether there will be need for projectors among others.

Additionally, it is important to ask questions as it not only arouses the interest of the audience but assists the speech presenter in carrying the audience along. Also, good pronunciation of words, appropriate choice of words, body language, proxemics, cheerful disposition, fluency and even gratitude the audience at the end of the speech make the speech presenter competent in his presentation.

\section{AUdiEnCE ANALYSIS}

Audience Analysis is a deliberate attempt made to ascertain and examine who the expected recipient or recipients of a speech is/are. Rao (2017) opines that audience Analysis is an important aspect of speech writing and speech delivery. If the analysis of the audience is not carefully done, it may lead to the speech not being effective. The beauty of a speech does not lie on how eloquent the presenter is or how technical the writer is. The audience is the recipient of the speech. The writer is not writing for himself but rather for the audience. So analysis of the audience should be paramount in any speech endeavor.

In audience analysis, the speech writer should be knowledgeable about the listeners' age and experience (Rao, 2007) if for example the audience is made up of the youths, topics like adverse effects of drug abuse or the dangers of engaging in student riot may be suitable for them. Also gender should be considered when engaging in audience analysis. The speech writer should ensure that the speech relates to both male and female, language usage that may be derogatory to either gender should be avoided among others. Also, the backgrounds of the audience which include the ethnic group, culture and religion of the audience should be ascertained by the speech writer. Once the speech writer has mastery of the composition of the audience, he would guard against using languages that will offend some members of the audience. For example, eating of snail may be forbidden in a particular culture while in some, it may be one of their favorites.

Hence, the onus is on the speech writer to have audience analysis in writing or presenting his speech so that he will not end up writing what will condemn his audience. Also, in writing and presenting speeches, religion of the target audience should be analyzed. In an audience where there are Muslims and Christians together, the wearing of hijab should not be condemned out rightly so as to avoid creating problems which may lead to the speech not being effective. The writer of the speech should note that his audience ranges from one person to millions of people hence, the need to do audience analysis before writing and presenting the speech. The writer should ask himself some questions ranging from: who is the recipient(s) of the speech? What are their- social involvement, educational status, gender, and the best means of writing and presenting the topic to the identified audience? In order to take care of the demographic analysis of the audience, the speech writer should gather information on: gender, educational attainment, occupation, marital status, and state of origin, ethnic group, language, religion and nationality of the audience (Kennison, 2013).

Also, in audience analysis, the speech writer should know the interest level of the audience. In doing this, he should ascertain the interest of the audience on the topic and arouse it so that their attention could be captured appropriately (Richards \& Schmidt 2002). It will not benefit both parties (the speech presenter and the audience) if the interest of the audience is not centered on the speech presentation. On the part of the audience, it will lead to waste of time and for the presenter, it may be termed that the he is not competent.

Still on the analysis of the audience, the speech writer should have knowledge of the size of the audience to avoid being thrown off balance especially when one is expecting a small group only to see thousands as audience. Again, time limit should be considered when writing speeches. This will assist the speech writer to throw away materials or points that are not suitable for the speech.

\section{RESEARCH QUESTIONS}

1. What is the level of knowledge Senior Secondary students have on speech writing?

2. Do Senior Secondary Students have the skill in audience analysis?

3. What knowledge and skill do secondary school students exhibit in speech delivery?

\section{METHOD}

\section{Research Design}

The study adopted the descriptive survey research design. This is cross-sectional in approach. The reason for using this design was as a result of the fact that the study observed the sample variables and found out that the behavioral patterns of the respondents across selected schools. The study investigated the level of speech delivery, audience analysis and speech writing among Senior Secondary school students precisely those in senior class two and three (SS2 and SS3) of the selected schools.

\section{Participants}

Purposive Sampling Technique was used to select one hundred and fifty (150) from three secondary schools in Ikenne Local Government Area, Ogun State. The Schools were: Ikenne Comprehensive Secondary School, Isanbi Comprehensive Secondary School and Ilishan High School. Total enumeration was used to get all the English language students in the stated schools

\section{Instrument}

Knowledge of speech writing, audience analysis and speech delivery of senior secondary school students were measured with self-constructed questionnaire tagged "Knowledge of Speech Writing, Audience Analysis and Speech Delivery Scale". The questionnaire was sectioned into two parts that is Section A, consisting of questions covering demographic information of the respondents such as name of school, sex, class levels of students and the ages of the respondents.

Section B is on students' knowledge of speech writing, audience analysis and speech delivery. It is a structured questionnaire in which thirty items were presented on four point scale in ordinal form. The four levels on the scale are: Always, Sometimes, Rarely and Never. The speech writing knowledge listed on the scale are ten items example, the audience analysis 
knowledge listed are ten while the speech delivery knowledge listed are ten also. The responses were scored: Always $=4$ points, Sometimes $=3$ points, Rarely $=2$ points and Never $=1$ point respectively. In order to ascertain the reliability of the instrument, the Cronbach method was adopted. The reliability coefficient was calculated and the Cronbach Alpha was used to determine the level of validity.
Data were analyzed using descriptive statistics of mean and standard deviation.

\section{RESULTS AND DISCUSSION}

Research Question One: What is the level of knowledge of the selected Senior Secondary Students on speech writing?

\section{Data Analysis}

Table 1: Senior Secondary students Level of knowledge on speech writing

\begin{tabular}{|c|l|l|l|l|}
\hline S/N & Speech Writing & $\bar{x}$ & St.D & Remark \\
\hline 1. & $\begin{array}{l}\text { I get suitable topics before engaging in speech } \\
\text { writing }\end{array}$ & 2.7133 & .75384 & Accept \\
\hline 2. & I use evidence to back what I am writing & 2.3800 & .77434 & Accept \\
\hline 3. & $\begin{array}{l}\text { I disregard materials that are not relevant to the } \\
\text { speech }\end{array}$ & 2.2200 & .86599 & Accept \\
\hline 4. & I try to be logical in speech writing & 2.1200 & .81034 & Accept \\
\hline 5. & $\begin{array}{l}\text { I write suitable introduction before the main } \\
\text { speech }\end{array}$ & 2.2800 & .65661 & Accept \\
\hline 6. & $\begin{array}{l}\text { I do not withhold information that might be } \\
\text { relevant to the audience when writing }\end{array}$ & 2.3467 & .67542 & Accept \\
\hline 7. & $\begin{array}{l}\text { I do not promote something as true which the } \\
\text { audience know to be false or fake }\end{array}$ & 2.2400 & .79157 & Accept \\
\hline 8. & $\begin{array}{l}\text { I do not reveal embarrassing details about people } \\
\text { when writing speech }\end{array}$ & 2.2333 & .71809 & Accept \\
\hline 9. & $\begin{array}{l}\text { I write with simple language during speech } \\
\text { writing }\end{array}$ & 2.0067 & .81510 & Accept \\
\hline 10. & I try to avoid exaggerations during speech writing & 2.0067 & .89365 & Accept \\
\hline
\end{tabular}

Source: Field Survey, 2020

Table 1 reveals the respondents' level knowledge on speech writing. From the table, the criteria mean is $2(1+2+3=6 / 3=2)$, this invariably implies that any mean value less than 2 implies that the statement is not accepted, but the statement is assumed accepted with a mean value of 2 and above. Hence, the table shows that on the average the respondents get suitable topics before engaging in speech writing. They also used evidence to back what their writing. They accepted that they try to be logical in speech writing, they write suitable introduction before the main speech and they do not withhold information that might be relevant to the audience when writing. On the average, the respondents accept that do not promote something as true which the audience know to be false or fake. They also accepted that they do not reveal embarrassing details about people when writing speech, accept that write with simple language during speech writing and they try to avoid exaggerations during speech writing.

Research Question Two: Do Senior Secondary Students have the skill in Audience Analysis?

Table 2: Senior Secondary Students level of skill in audience analysis

\begin{tabular}{|c|l|l|l|l|}
\hline & Audience analysis & $\overline{\boldsymbol{x}}$ & St.D & Remark \\
\hline 1. & $\begin{array}{l}\text { I know the audience and recipients of the speech before } \\
\text { speech presentation }\end{array}$ & 2.2267 & .86813 & Accept \\
\hline 2. & I consider the audience age before presentation of speech & 2.2800 & .75191 & Accept \\
\hline 3. & I consider their educational background & 1.8400 & .96988 & Reject \\
\hline 4. & I consider their religious background & 2.0600 & .86877 & Accept \\
\hline 5. & I consider their cultural background & 2.0600 & 1.03126 & Accept \\
\hline 6. & $\begin{array}{l}\text { I monitor the interest level of the audience and make } \\
\text { adjustments }\end{array}$ & 2.0000 & .88991 & Accept \\
\hline 7. & I capture the interest of the audience and maintain it & 2.0533 & .79247 & Accept \\
\hline 8. & $\begin{array}{l}\text { I try to satisfy the needs and desires of the audience } \\
\text { concerning the speech }\end{array}$ & 1.9467 & .97476 & Reject \\
\hline
\end{tabular}




\begin{tabular}{|c|l|l|l|l|}
\hline 9. & $\begin{array}{l}\text { I establish credibility of my personality at the beginning of } \\
\text { the speech }\end{array}$ & 2.1733 & .76629 & Accept \\
\hline 10. & I do not condemn responses and questions from the audience & 2.3200 & .75369 & Accept \\
\hline
\end{tabular}

Source: Field Survey, 2020

Table 2 reveals the respondents' level of skill in audience analysis. With criteria mean of 2 , the table shows that on the average, the respondents accepted that they knew the audience and recipients of the speech before speech presentation and accept they consider the audience age before presentation of speech. However, on the average, the respondents do not accept that they consider audience educational background. But they consider their religious background and cultural background. They monitor the interest level of the audience and make adjustments and capture the interest of the audience and maintain it. They, however, do not try to satisfy the needs and desires of the audience concerning the speech. The table reveals that, on the average, they establish credibility of my personality at the beginning of the speech and they do not condemn responses and questions from the audience. Research Question Three: What knowledge and skill do Senior Secondary students exhibit in speech delivery?

Table 3: The level of knowledge and skill secondary school students have in speech delivery

\begin{tabular}{|c|l|l|l|l|}
\hline & Speech delivery & $\overline{\boldsymbol{x}}$ & St.D & Remark \\
\hline 1. & $\begin{array}{l}\text { I ensure the physical setting and venue of the speech is determined } \\
\text { before speech delivery }\end{array}$ & 2.0933 & .65893 & Accept \\
\hline 2. & I make provision for public address system during speech delivery & 1.8267 & .59918 & Reject \\
\hline 3. & I use projectors in delivering my speech & 1.7800 & .78467 & Reject \\
\hline 4. & $\begin{array}{l}\text { I ask questions to arouse the interest of the audience during speech } \\
\text { delivery }\end{array}$ & 1.8267 & .59918 & Reject \\
\hline 5. & I practice and rehearse my speech before delivery & 2.0533 & .52822 & Accept \\
\hline 6. & I proofread my speech before delivery & 1.9867 & .75961 & Reject \\
\hline 7. & I pronounce words correctly during speech delivery & 1.7133 & .99216 & Reject \\
\hline 8. & $\begin{array}{l}\text { I ensure that my gestures and points are synonymous during } \\
\text { speech delivery }\end{array}$ & 1.6667 & .93885 & Reject \\
\hline 9. & I maintain cheerful disposition during speech delivery & 1.5600 & .69010 & Reject \\
\hline 10. & $\begin{array}{l}\text { I do appreciate the audience after speech delivery for sacrificing } \\
\text { their time and attention to listen }\end{array}$ & 1.3467 & .81912 & Reject \\
\hline
\end{tabular}

Source: Field Survey, 2020

Table 3 reveals the respondents' level of knowledge and skill on speech delivery. With criteria mean of 2 , the table shows that on the average, the respondents accept that they ensure the physical setting and venue of the speech is determined before speech delivery. However, on the average, the respondents do not accept that they make provision for public address system during speech delivery, they do not use projectors in delivery speech and they do not ask questions to arouse the interest of the audience during speech delivery but they accept that they practice and rehearse their speech before delivery. The analysis reveals that, on the average, the respondents do not proofread their speech before delivery and they do not pronounce words correctly during speech delivery. It could be deduced from the result that, on the average, the respondents do not accept that they ensure that their gestures and points are synonymous during speech delivery. They do not maintain cheerful disposition during delivery and they also do not appreciate the audience after speech delivery for sacrificing their time and attention to listen.

Table 4:Summary of mean measure of the explanatory variables.

\begin{tabular}{|l|l|l|l|l|}
\hline & $\begin{array}{l}\text { Max Point of scale of } \bar{x} \\
\text { measure }\end{array}$ & \% of Max point & Std. Deviation \\
\hline Speech Writing & 30.00 & 22.5467 & 75.2 & 6.04301 \\
\hline Audience analysis & 30.00 & 20.9600 & 69.9 & 7.19702 \\
\hline Speech delivery & 30.00 & 17.8533 & 59.5 & 5.28057 \\
\hline
\end{tabular}

Source: Computed from field survey, 2020

The construct measuring level of knowledge on speech delivery among the respondents was measured on a 30-point rating scale and the result shows that the respondents scored mean of 22.5 \pm 6.0 this gives the level of knowledge of speech writing score of $75.2 \%$. From the result, the researcher deduced that the respondents had a high level knowledge of speech writing. The construct measuring the level of skill in audience analysis among the respondents was measured on 30-point rating scale. The result showed that the respondents scored mean of $21.0 \pm 7.2$, this gives the level of skill in audience analysis score of $69.9 \%$. This showed 
that the respondents had a low skill in audience analysis. According to Agbede, Kio and Adeyemo (2019), the acceptance level is $70 \%$ and above, whiles any level less than $70 \%$ is said to be low.

The construct measuring the level of knowledge and skill in speech delivery among the respondents was measured on 30-point rating scale. The result showed that the respondents scored mean of $17.9 \pm 5.3$, which gave the knowledge and skill level in speech delivery score of $59.5 \%$. This showed that the respondents had a very low level knowledge and skill in speech delivery.

\section{DISCUSSIONS}

The study examined the knowledge of students on speech writing, audience analysis and speech delivery among Senior Secondary School students in Ikenne Local Government Area of Ogun State. Out of the three research questions used in the study, two showed that students had low level of knowledge in audience analysis and speech delivery. One research question showed that the students had high level of knowledge in speech writing. The above findings are evident in the result of the students' knowledge of audience analysis like: knowing the audience and recipients of the speech before speech presentation, considering educational background of the audience, religious background, how many people will make up the audience, provision of public address system etc. Also, asking questions to arouse the interest of the audience during speech delivery, proofreading the speech before delivery etc. The findings support Jill (2017) that the speaker needs to ascertain the number of people that will form the audience, whether there will be need for public address system or not among others.

\section{CONCLUSION AND RECOMMENDATIONS}

The study was carried out to ascertain the level of knowledge of speech writing, audience analysis and speech delivery of selected Senior Secondary schools students in Ikenne Local Government Area of Ogun State. One hundred and fifty questionnaires were distributed to one hundred and fifty students in the three schools on their knowledge of speech writing, audience analysis and speech delivery. Based on the findings, this study recommended that English language teachers should expedite actions to improve the techniques used in speech delivery and audience analysis. Also, the school authorities should supply speech delivery tools (computers, etc) to enhance the performance of students in speech delivery and audience analysis.

\section{REFERENCES}

[1] Adler, R.B. and Elmhorst J.M. (2008) Communicating at Work: Principles and Practice of Business and the Professions. Boston: McGraw Hill

[2] Agbede K, Kio J. and Adeyemo N. (2019) "Correlates of Intention to Discontinue Female Genital Mutilation in Osun State: Implication for Women-Well Being" Journal of Public Health Nursing. 36(5) 615-622

[3] Alimole, O. (2002) Speech Writing: A Guide for Diplomats and Public Officers. Ibadan. Heinemann Educational Books (Nigeria) Plc

[4] Cervantes C. \& Simon J. (2018) "Restoration and Efficacy of the Neural Processing of Continuous Speech Are Prompted by Prior Knowledge". Frontiers in System Neuroscience 12(56) 56

[5] Gallo, C. (2014) Talk Like TED: The Nine Public Speaking Secrets of the World's Top Minds. New York. St Martin's Press

[6] German Kathlean M. (2010) Principles of Public Speaking. Boston. Allyn and Bacon

[7] Gerry P. (2015) International Encyclopedia of Language and Social Interacting

[8] Gregory H. (2010) Selected Chapters from Public Speaking for Colleges and Career, ninth edition. Boston: McGraw-Hill Learning Solutions

[9] Jill S. (2017) Delivery Skills for Public Speaking. Retrieved July 20, 2020 from https://www.entrepreneur.com/article/290445

[10] Kamalu, I (2018). Stylistics. Kraft Book Limited.

[11] Kennison, S. (2013) Introduction to Language Development. Los Angeles: Sage

[12] Lucas, S.E. (2001) The Art of Public Speaking. Boston: McGraw-Hill Higher Education

[13] Okwara, M.O. ( 2012). "A Study of Factors Related to Achievement in Written Composition Among Secondary School Students in Busia District. Unpublished Thesis". Kenyatta University

[14] Rao, P.S. (2017) "The Characteristics of Effective Writing Skills in English Language Teaching" Research Journal of English. 2(2) 7586.www.rjoe.org.in

[15] Richards, J.C. and Schmidt, R. (2002) Language Teaching and Applied Linguistics. Edinburgh: Pearson Education Limited

\section{AUTHORS}

First Author - James, Nma C. PhD, Department of Education, School of Education and Humanities, Babcock University, Ilishan Remo, Ogun State, Jamesn@ babcock.edu.ng, 08161261437

Second Author - Kalejaye, S. Abiola . PhD, Department of Languages and Literary Studies, School of Education \& Humanities, Babcock University, kalejaiyeab@babcock.edu.ng 07067011470

Third Author - Kparou, Hanoukoume Cyril (PhD), Department of Languages and Literary Studies, School of Education \& Humanities, Babcock University, kparouh@babcock.edu.ng, 07054623945 